\title{
Influence of Local Microstructure on Stresses, Durability and Fracture Mechanics of Cast Iron Components
}

\author{
Corinna Thomser ${ }^{1, a^{*}}$, Jakob Olofsson ${ }^{2, b}$ and Vitalii Gurevitch ${ }^{1, C}$ \\ ${ }^{1}$ MAGMA Gießereitechnologie GmbH Aachen, Germany \\ ${ }^{2}$ Jönköping University, Sweden \\ ac.thomser@magmasoft.de, ${ }^{\mathrm{b}}$ jakob.olofsson@ju.se, ${ }^{\mathrm{c}} \mathrm{v}$. gurevich@magmasoft.de
} Keywords: cast iron, microstructure, fatigue, durability, casting process simulation, S-N curves,
Woehler curves, fracture toughness, mechanical properties, Failure Assessment Diagram (FAD)

\begin{abstract}
Cast iron components show a large variety of different microstructures in dependence on chemical composition, inoculation and cooling conditions. In conventional static and dynamic calculations as well as in fracture mechanics assessment of cast iron components, the influence of local microstructure on the overall behavior of the component is not considered. Usually one material dataset is applied for the whole material. The paper describes recent developments in the field of the prediction of local microstructure and its correlation to local stress-strain, fatigue durability as well as fracture toughness. The benefit of combining casting process simulation with lifetime predictions and fracture mechanics assessment is shown for selected examples. By integrating casting process simulation, microstructure modelling, local material characterization and load analysis, a simulation based approach for predicting the behavior and performance of cast iron components already during the design stage is enabled. Thus, the local assessment helps designers to assess risks and strive for light weight designs before the casting is made.
\end{abstract}

\section{Introduction}

A wide range of strength levels with good ductility are the known advantages of cast iron materials. Therefore, they are used in various applications in wind energy and mechanical engineering applications in general. Cast iron materials are characterized by a large diversity in microstructure, e.g. differences in graphite distribution and morphology as well as varying strength levels corresponding to the different ferrite and pearlite contents of different cast iron materials. Chemical composition, inoculation methods and local cooling conditions due to casting design and casting process parameters play a major role for the evolution of the local microstructure in cast iron materials.

In conventional static and dynamic calculations as well as in fracture mechanics assessment of cast iron components, the influence of the local microstructure is not taken into account. One material dataset is usually applied for the whole component; the influence of local microstructure on the overall performance of the components is not considered. This leads on the one hand to high uncertainties concerning local failure risks or on the other hand to an unnecessary excessive weight of the component due to high safety margins resulting in high part costs.

Recent developments in the field of the correlation of local microstructure to local stress-strain, fatigue durability as well as fracture toughness are described in the subsequent sections in order to illustrate the material potential of cast iron.

\section{Characterization of Microstructure-Based Tensile Behavior}

For many years, considerable amount of research has contributed to understand the effect of different solidification conditions and microstructural parameters on specific mechanical properties as yield strength, ultimate tensile strength and elongation to failure of cast iron materials. Much work has also been aimed at generating quantitative knowledge, i.e. establishing a numerical model that quantitatively relates microstructural features or solidification conditions to these basic material 
properties. While specific material properties as yield strength are highly important from the metallurgical perspective to understand the material, as well as for quality and process control, recent works have emphasized the importance of understanding how these properties vary throughout a cast component. In order to make cast irons more attractive for high performing components, it is important that this understanding can be provided in a quantitative way to designers and simulations of cast components in use. In order to enable load analysis on all types of load cases, it is important to characterize the entire elasto-plastic behavior rather than just the basic mechanical properties.

There are several different constitutive models available for representing the elasto-plastic behavior in a suitable way for load analysis, see e.g. [1]. For different types of cast irons, the Ludwigson equation has been shown to accurately describe the different plastic behaviors found in complex castings [2-3]. The Hollomon equation has been found to accurately describe the later stages of hardening, where the strain hardening exponent can be seen as a measure of the entanglement of dislocations. The strain hardening exponent describes the shape of the plastic curve, while the strength coefficient indicates the strength level or height of the curve.

The Ludwigson equation is formulated as an extension of the Hollomon equation, which adds an exponential correction term, where the exponent is linearly dependent on the plastic strain. This correction term thus decays as the plastic strain increases, and is thus related to the low plastic strains phenomena in cast irons, i.e. the small strain crack initiation and graphite debonding/fracture.

By studying how the four parameters of the Ludwigson equation vary with microstructural changes, a semi-empirical method to relate microstructure to the entire tensile curve can be established. As examples, this type of models has been shown to yield good descriptions of the material behavior of a ductile iron alloy [2] as well as a high-silicon CGI alloy [3]. By implementing such models into casting process simulations in MAGMASOFT $^{\circledR}$, so called microstructure-based tensile curves can thus be generated which describes the local material behavior throughout cast components of complex geometries, as illustrated in Figure 1.

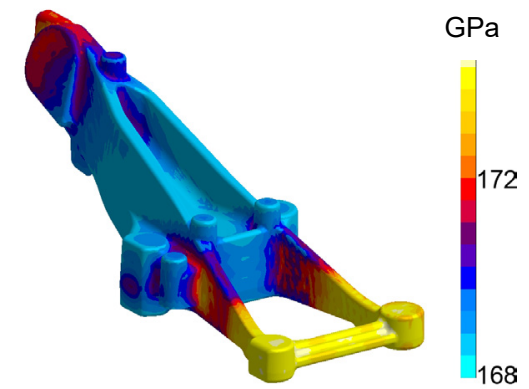

(a)

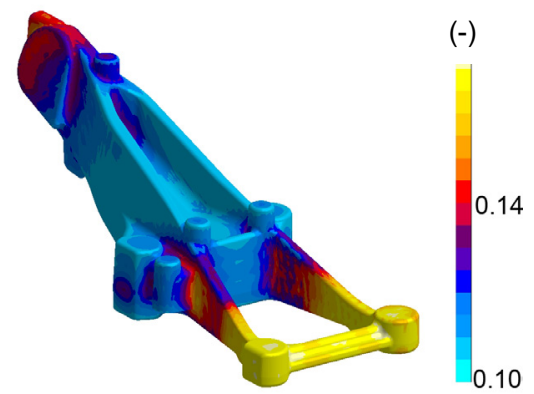

(b)

Figure 1: Simulated microstructure-based variations in a) Young's modulus and b) strain hardening in a ferritic-pearlitic ductile iron component [4].

\section{Stress-Strain Simulations Using Microstructure-Based Behaviour}

Once the parameters of the constitutive model, e.g. the Hollomon or the Ludwigson equation, are known, the elasto-plastic curve for the material can be determined. In casting process simulation, this can be done on the element level, i.e. the parameters for the tensile curve are locally determined in each element of the mesh. In order to make use of this data in subsequent load analysis, this local data has to be transferred into local material definitions in the FE model.

In the so called closed chain of simulations for cast components [4-5], a technique to generate local material definitions based on the elemental values of the Ludwigson equation predicted by a casting simulation was established. The values from the casting simulation are mapped to the FE mesh and serve as input to a procedure which generates the material definitions required for the specific FE solver. 
The local variations in material behavior may have a significant impact on the distribution of stresses and strains in a ductile iron component, as illustrated in Figure 2. If these local variations are not considered in load analysis, incorrect results and conclusions about the performance of the cast component may thus be obtained.

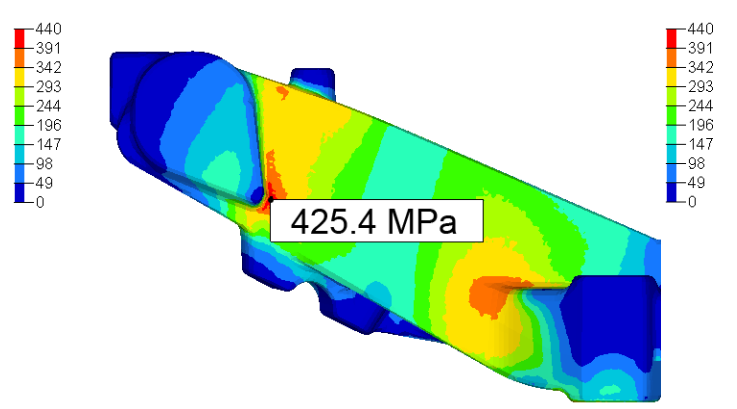

(a)

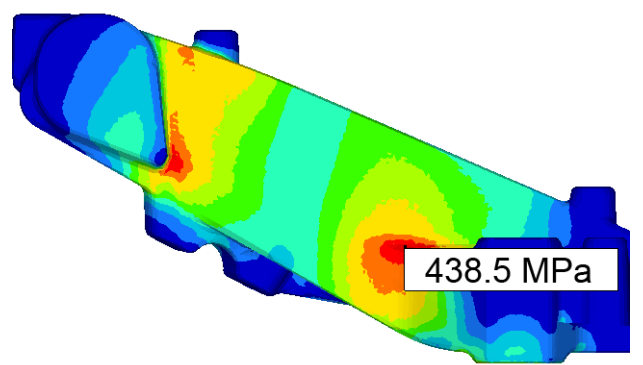

(b)

Figure 2: Simulated distribution of von Mises stress in the ductile iron component using a) microstructure-based material data and $b$ ) homogenized material data [6]. If the microstructural variations are not considered, another location of maximum stress is predicted.

\section{Microstructure-Based Durability Predictions}

The local variations in microstructure lead not only to local differences in static mechanical properties; also the fatigue durability is influenced by it. In conventional design processes the local microstructure of cast iron is not taken into account. Usually one S-N curve (Woehler curve) is applied for the whole component.

The procedure to connect casting process simulation with fatigue calculations, where local microstructure and local fatigue durability is considered, is presented in Figure 3. In the German research project MABIFF, the link between casting process simulation and cyclic material properties was established for different cast iron materials [7]. The framework of this research project included the evaluation of major microstructure characteristics of a ductile iron (GJS-400) and a compacted graphite iron (GJV-450) and their impact on component lifetime.

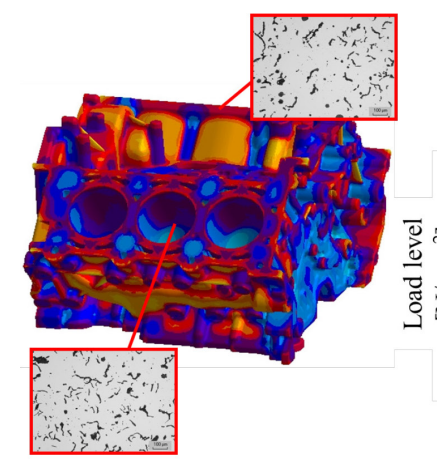
Casting simulation / Microstructure calculation

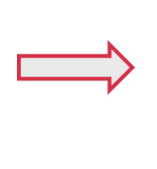

Woehler curves (S-N curves) in dependence on microstructure
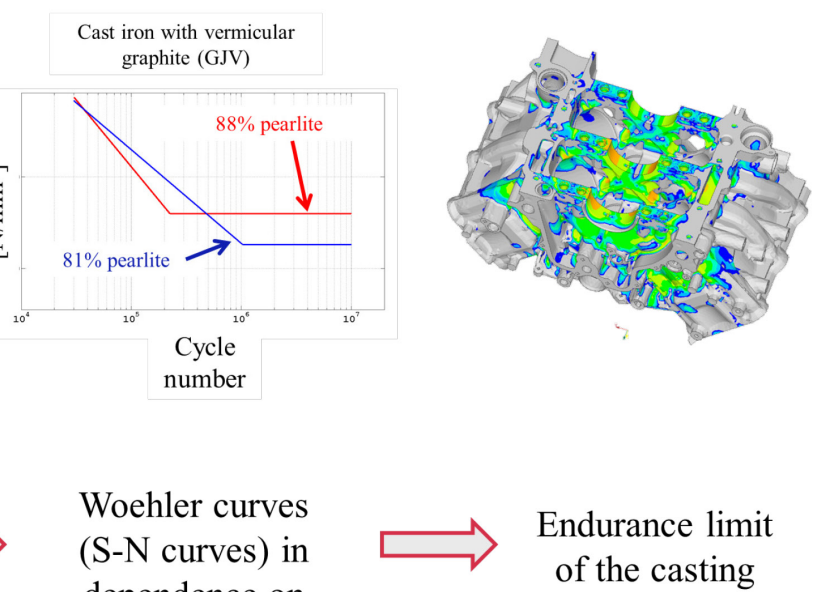

Figure 3: From casting process simulation to improved durability calculation under consideration of the local microstructure of cast iron.

To realize a complete chain of information, both materials were evaluated by comprehensive cyclic load testing using tension-compression and cyclical bending tests for various microstructures. The local microstructure was evaluated as well using automatic image analysis. Furthermore, 22 characteristics were evaluated, specifically the number, shape and size of the graphite particles, as 
well as the ferrite/pearlite ratio. The identified microstructure characteristics were also used to validate the accuracy of the simulated results or the predictions generated with the casting process simulation tool used in this project.

Aside from the shape of the graphite particles and the number of particles corresponding to the particle distance, the local pearlite content plays an important role for the local fatigue strength. The mathematical correlation between predicted and measured durability values for samples in tensioncompression runs is presented in Figure 4. These findings were implemented into the MAGMASOFT $^{\circledR}$ simulation software. Based on the mathematical correlation it is possible to predict durability values with the consideration of process conditions at any location in a casting. The local durability values can easily be transferred into lifetime analysis programs as shown in Figure 5.

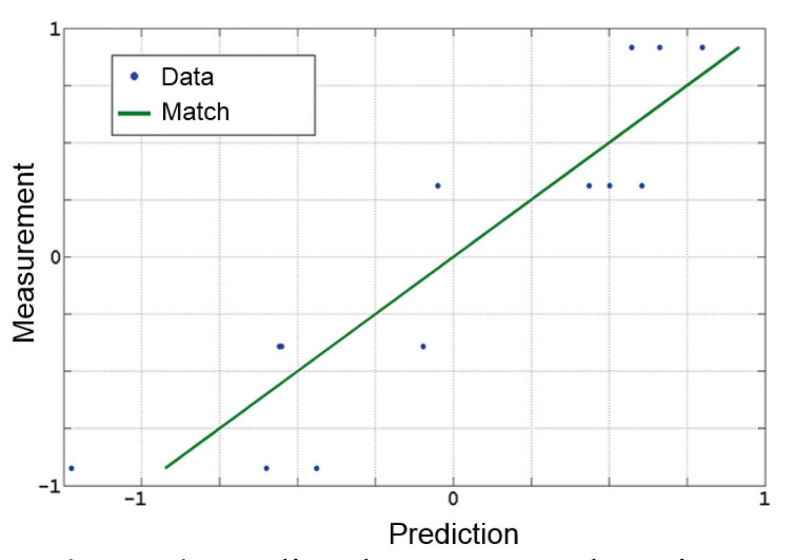

Figure 4: Predicted vs. measured tensioncompression durability values for ductile iron.

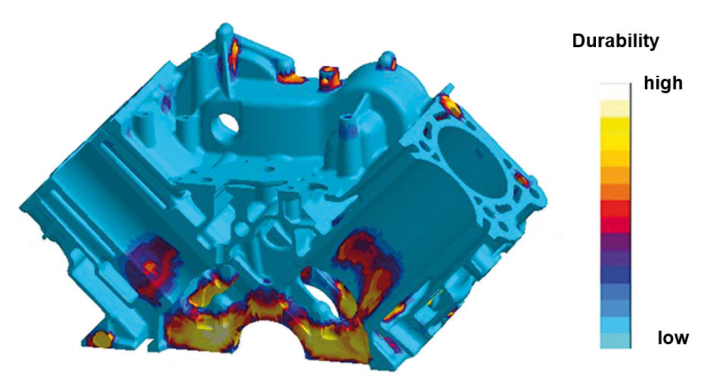

Figure 5: Calculated durability values as function of the local microstructure prediction.

Except for quantitative differences in durability values it is also possible to clearly define potentially weak areas. Figure 6 compares the conventional (microstructure independent) and the improved prediction of crack initiation areas in the bearing support. Only the microstructure distribution based durability calculation predicts the correct location of weak spots in the casting.

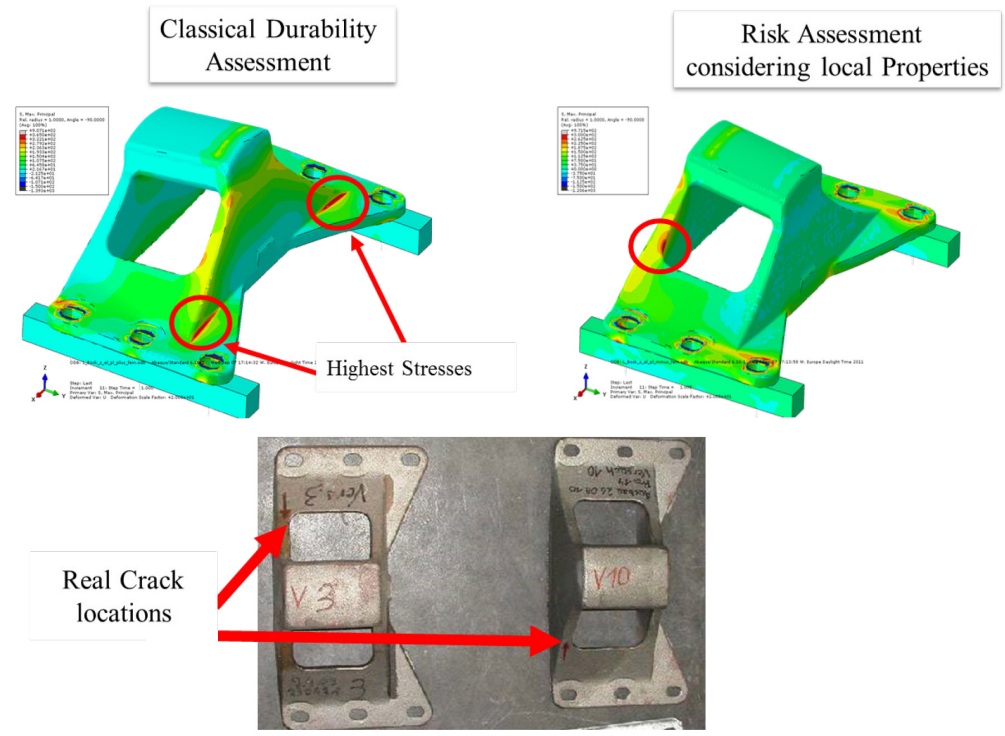

Figure 6: Comparison of weak in a bearing support. Only the new method shows the correct crack initiation locations. 


\section{Microstructure-Based Fracture Toughness}

Within the VDMA guideline 23902 it is recommended to apply casting process simulation for fracture mechanics assessment for planetary carriers of wind energy turbines [8]. Currently no standard method is established to include the results of casting process simulation in fracture mechanics assessment. Therefore, a new proposal was made and a new methodology was described to integrate casting process simulation into fracture mechanics assessment of iron castings typically used for wind energy turbines [9]. A typical planetary carrier casted with the material GJS-400 was used as a demonstrator.

Correlations between the local microstructure distribution and the mechanical properties together with fracture toughness have been utilized. In addition, also residual stresses from casting process simulation are taken into account for fracture mechanics assessment. Another important input parameter for the fracture mechanics analysis is the crack size, which has been related to the porosity predictions of the casting process simulation. Furthermore, the fracture toughness is required. Since experiments are time consuming, expensive and measured values are dependent on the sample position and local microstructure and do not reflect the diversity of microstructures in large cast iron components, other sources for the calculation of fracture toughness are required.

In literature, the effect of microstructure on fracture toughness is reported [10-11]. Different correlations have been derived depending on what parameters were identified to have the highest influence on the measured toughness values. From a microstructural point of view, Baer mentioned that the major influencing factors on fracture toughness are the distance between the graphite particles, the shape factor of graphite as well as the pearlite content [10]. In the later developed correlation elongation and yield strength $(\mathrm{Rp} 0,2)$ taken from uniaxial tensile tests are considered as well [11].

Average distance of nodules in $\mu \mathrm{m}$

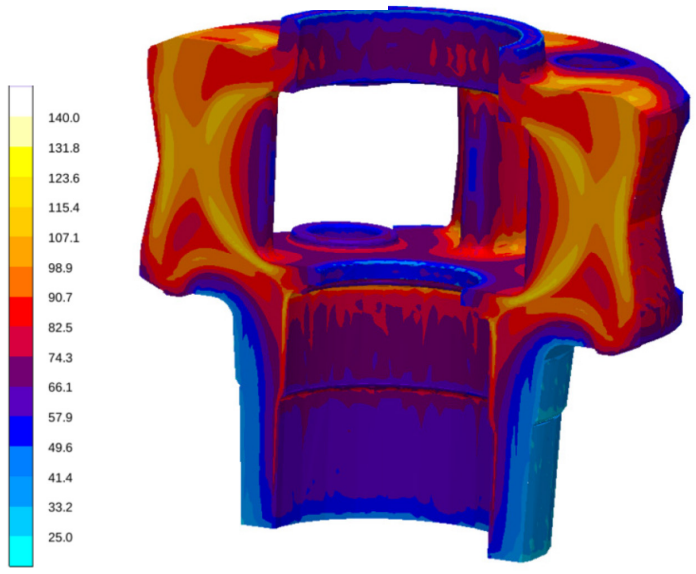

Figure 7: Average distance between nodules predicted by casting process simulation for GJS-400.
Fracture toughness $\mathrm{J}_{\mathrm{i}, \mathrm{SZW}}$ in $\mathrm{N} / \mathrm{mm}$

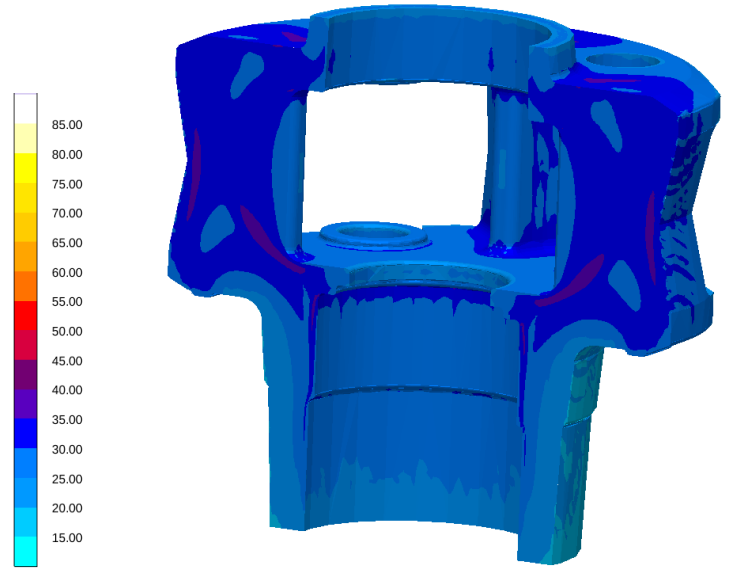

Figure 8: Simulated fracture toughness, $\mathrm{J}_{\mathrm{i}, \mathrm{SZW}}$ in $\mathrm{N} / \mathrm{mm}$.

The latest correlation and also the most conservative approach for this case of the planetary carrier (lowest fracture toughness values) to link local microstructure and mechanical properties to fracture mechanics is given in the approach by Pusch [11]. Besides the pearlite content and the particle distance of nodules, the material properties elongation at fracture and yield strength are taken into account. Mainly the particle distance (Figure 7) between the graphite particles governs the local distribution of fracture toughness. The other parameters like pearlite content, elongation at fracture and yield strength are nearly constant in the load case relevant area, distribution details can be found in the paper of Langenberg [9].

The calculated fracture toughness is shown in Figure 8. Calculation details can be found in the publication of Langenberg [9]. The fracture mechanics calculation is based on calculated stress 
distributions across the wall thickness in the critical area. The maximum tensile design stress was taken to be $160 \mathrm{MPa}$ for the applied load case. The crack geometry is derived from the worst-case scenario of the porosity prediction from casting process simulation, by transferring the given result of the pore size volume into one flat cigar type of ellipsoid with three axes $a, b$ and c [9].

Figure 9 provides the crack geometry taken into account for the calculation. It is assumed that the porosity predicted in casting process simulation is concentrated in one large single defect in the critical area. The position of the crack was selected near the surface with $d=5 \mathrm{~mm}$ subsurface according to VDMA guideline 23902 [8].
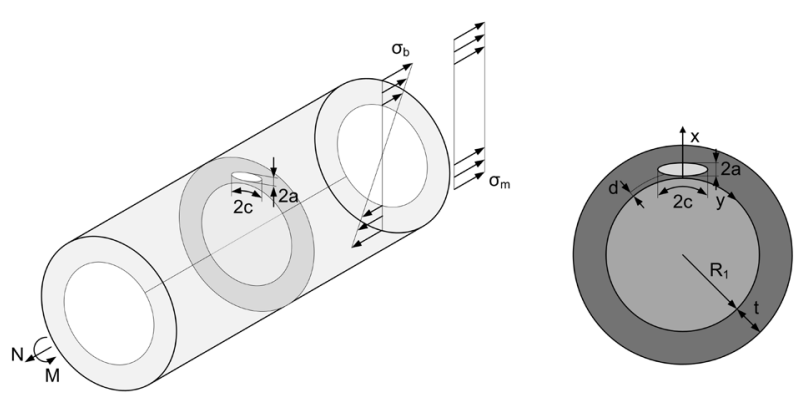

Geometry parameters of the defect

Defect size for the ratio $\mathrm{a} / \mathrm{c}=0,2$

Volume $\quad 9 \mathrm{~cm}^{3}$

Axis a $\quad 9,5 \mathrm{~mm}$

Axis c $\quad 47,5 \mathrm{~mm}$

Dimensions of the pipe model

Inner radius $\mathrm{R}_{1} \quad 272,5 \mathrm{~mm}$

Wall thickness $\mathrm{t} \quad 150 \mathrm{~mm}$

Figure 9: Fracture Mechanics Models applicable for planetary carriers: embedded cracks.

For this model the stress intensity factor and the limit load can be calculated from established formulas given in handbooks or the cited guidelines [12-14]. The calculation software, IWM Verb, Version 8-1 was used [15]. The combination with the casting process simulation is given on the resistance side. The parameters mainly taken from the casting process simulation are presented in Table 1.

Table 1: Input variables for the material (Resistance Side).

\begin{tabular}{|c|c|c|c|}
\hline Parameter & $\begin{array}{l}\text { Used } \\
\text { values }\end{array}$ & Source & $\begin{array}{l}\text { Effect on Fracture } \\
\text { Mechanics calculation }\end{array}$ \\
\hline \multicolumn{4}{|l|}{ Strength } \\
\hline Yield strength Rp0,2 [MPa] & 278 & Simulation & Coordinate $\mathrm{L}_{\mathrm{r}}$ \\
\hline Tensile strength $\mathrm{Rm}[\mathrm{MPa}]$ & 421 & Simulation & \\
\hline \multicolumn{4}{|l|}{ Toughness } \\
\hline Young's modulus E [GPa] & 168 & Simulation & \multirow[t]{2}{*}{ Transfer J into $\mathrm{K}_{\text {mat }}$} \\
\hline Poisson ratio $v$ & 0,275 & DIN EN 1563 & \\
\hline J- Integral $[\mathrm{N} / \mathrm{mm}]$ & 20,94 & Simulation, see Figure 8 & \multirow[t]{2}{*}{ Coordinate $\mathrm{K}_{\mathrm{r}}$} \\
\hline $\mathrm{K}_{\text {mat }}[\mathrm{MPa} \sqrt{\mathrm{m}}]$ & 62 & $\begin{array}{l}\text { Calculation formula } \\
\mathrm{K}_{\mathrm{mat}}=\left[\mathrm{J}_{\mathrm{c}, \mathrm{i}} * \mathrm{E} /\left(1-\mathrm{v}^{2}\right)\right]^{0,5}\end{array}$ & \\
\hline
\end{tabular}

The results of the calculations are shown in Figure 10 for the load case of the Serviceability Limit State under consideration of different levels of residual stresses. The Failure Assessment Diagram for this load case (FAD) can be read as follows: For any fracture problem a design point is based on input variables for the material (strength and toughness), crack and component geometry and loading. Any point falling inside the diagram means safe conditions, any point outside (circles) unsafe conditions. For ES 10 (green square) safe conditions are predicted. The simulated residual stresses in the casting process are close to $20 \%$ of yield strength, so they correspond to ES20 [9]. The design point falls closely below the limit line. For this load case the component is still safe under consideration of residual stresses from the casting process, the yellow triangle falls inside the safe regime of the FAD, but the design point is really close to the limit line. For ES 30 unsafe behavior is calculated, the design point (red square) falls outside the limit line of the FAD. The results for multiple other load cases are discussed in detail in literature as well as the calculation of the residual stresses in the casting process [9]. 


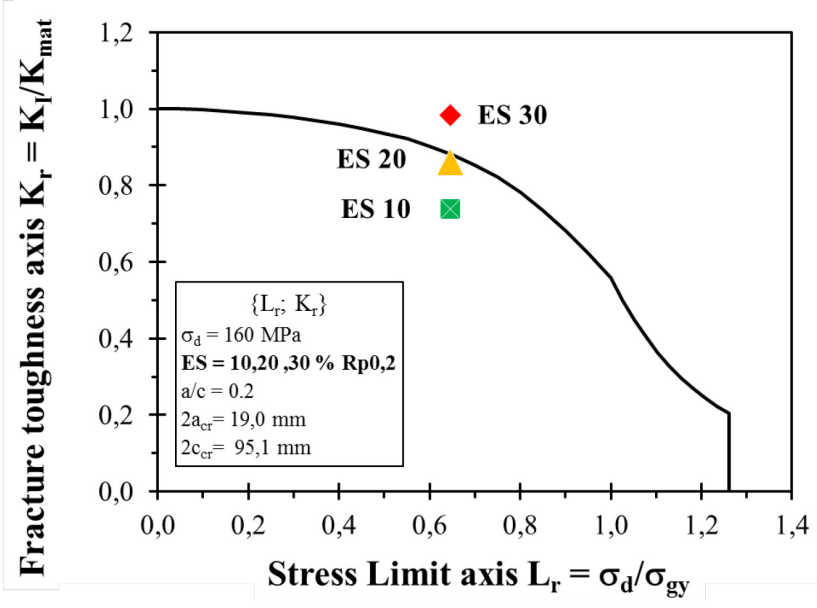

Figure 10: Fracture Mechanics Calculation of the Load Case SLS (Serviceability Limit

State) under consideration of residual stresses from the casting process in the planetary carrier.

In case of the prediction of unsafe behavior, different alternatives are possible:

1. Reduction of defects in casting process supported by casting process simulation

2. Increase of local fracture toughness by specific microstructure modification

3. Changes in design and/or loads of the planetary carrier

\section{Discussion}

Cast iron components show a large variety of different microstructures. The extent of these variations will vary depending on factors as type of casting, chemical composition and process conditions. Using recent developments in modelling and simulations, the local microstructure-based material behavior can be predicted and integrated into various types of simulations of the performance and durability of cast components. These simulations act to increase the accuracy of load analysis and enable the design of robust and high performing cast components with high efficiency for e.g. lightweight applications. Cast irons are competitive materials for many types of engineering applications, and using numerical simulation techniques the coupling between metallurgy and engineering design aspects can be integrated.

The effect of the local material behavior will highly influence the load distribution and fatigue behavior of cast components. The approaches described integrates the consideration of these effects into load analysis, which enables designers to better understand the importance of geometry changes on the component performance and find improved design and process solutions. This also enables tailoring of local behavior and performance by evaluating changes in geometry and casting process. Using this type of integrated casting and load analysis, it will also be possible to further enhance the component design using numerical geometry optimization techniques as outlined elsewhere [16-17].

\section{Conclusions}

Recent developments in modelling and simulations of local material performance of cast irons have been outlined. By coupling casting process simulations to load analysis, microstructure-based local material behavior can be predicted and utilized to design cast iron components with increased fatigue performance, high robustness and efficiency. Casting process simulation can also be included in fracture mechanics assessment. Thus, the local assessment helps designers to assess risks and strive for light weight designs before the iron casting is made.

\section{Acknowledgements}

Dr. J. Olofsson would like to acknowledge the Swedish Knowledge foundation for financial support of the CompCAST research profile at Jönköping University. 


\section{References}

[1] Z. Gronostajski, The constitutive equations for FEM analysis, J Mater Process Tech, 106 (2000), 40-44.

[2] I.L. Svensson, J. Olofsson, On microstructure-based mechanical behaviour of a ductile iron component, $10^{\text {th }}$ International Symposium on the Science and Processing of Cast Iron - SPCI10, 2014.

[3] R. Ghasemi, J. Olofsson, A.E.W. Jarfors, I.L. Svensson, Modelling and simulation of local mechanical properties of high silicon solution-strengthened ferritic compacted graphite iron, Int J Cast Metal Res, 30 (3) (2017), 125-132.

[4] J. Olofsson, I.L. Svensson, Incorporating predicted local mechanical behaviour of cast components into finite element simulations, Mater Design, 34 (2012), 494-500.

[5] J. Olofsson, I.L. Svensson, The effects of local variations in mechanical behaviour - Numerical investigation of a ductile iron component, Mater Design, 43 (2013), 264-271.

[6] J. Olofsson, I.L. Svensson, Casting and stress-strain simulations of a cast ductile iron component using microstructure-based mechanical behaviour, IOP Cong Ser-Mat Sci, 33 (2012).

[7] A. Heinrietz, J. Eufinger, W. Stets, J. Linn, A. Egner-Walter, J. Richter, G.-S. Leo, E. Fritsche, N. Zenker, F. Pollicino, Maßgeschneiderte Bauteileigenschaften durch Integration von Fertigungsund Funktionssimulation, Abschlussbericht BMBF Projekt Nr. 01R/0713, 2011.

[8] VDMA Guideline 23902: Guideline for fracture mechanical strength assessment of planet carriers made of nodular cast iron EN-GJS-700-2 for wind turbine gear boxes, 2014.

[9] P. Langenberg, C. Thomser, J.C. Sturm J.C., P. Kucharczyk, Integration of Casting Process Simulation into Safety-Oriented Component Design - Status and Outlook, Presented at CastTec Conference, November 2016, Darmstadt.

[10]W. Baer, Bruchmechanische Bewertung ferritischer Gußeisenwerkstoffe sowie artgleicher Schweißverbindungen bei statischer Beanspruchung, Dissertation TU Bergakademie Freiberg, 1996.

[11] G. Pusch, S. Henkel, P. Biermann, P. Hübner, A. Ludwig, P. Trubitz, T. Mottitschka, L. Krüger, Determination of fracture mechanics parameters for cast iron materials under static dynamic and cyclic loading, Dedicated to Professor Meinhard Kuna on the occasion of his 65th birthday.

[12]BS7910: Guideline on methods for assessing the acceptability of flaws in metallic structures, British Standard Institutions, 2013.

[13]FKM Heft 258, Bruchmechanischer Festigkeitsnachweis, 2009 (info: www.vdma/fkm)

[14]API RP 579-1 / ASME FFS-1: Fitness-for-Service, API Publishing Services, First edition, January 2016.

[15] IWM Verb 8-1, Fraunhofer Institut für Werkstoffmechanik Freiburg, 2016.

[16] J. Olofsson, K. Salomonsson, J. Johansson, A methodology for microstructure-based structural optimization of cast and injection moulded parts using knowledge-based design automation, Adv Eng Softw, 109 (2017), 44-52.

[17] R. Cenni, M. Cova, G. Bertuzzi, A methodology to consider local material properties in structural optimization, P I Mech Eng C-J MEC, 231 (issue 15) (2017), 2822-2834. 